\title{
INTERDENTAL PAPILLAE HEIGHT ASSESSMENT IN THE AESTHETIC ZONE OF THE MAXILLA
}

\author{
Irena Georgieva, Stefan Peev, Teodora Gerova, Mariya Miteva, Marieta Bazitova-Zlateva \\ Department of Periodontology and Dental Implantology, Faculty of Dental Medicine, \\ Medical University of Varna
}

\begin{abstract}
Open gingival embrasure occurs as a result of a deficiency of papilla apically to the contact point. Open gingival embrasures are a complex aesthetic and functional problem. Several risk factors lead to the development of an open gingival embrasure: aging; periodontal disease; ratio between the interdental bone and the interproximal contact point between adjacent teeth, length of the embrasure area, root angulations, and triangular-shaped crowns.

The study included 1088 interdental papillae in the aesthetic zone of the maxilla of 220 individuals. The height of the interdental papillae was measured according to the classification of Nordland \& Tarnow (1998).
\end{abstract}

The analysis of the results showed that the frequency and severity of height loss of interdental papillae increased with age.

Keywords: interdental papilla, maxilla, black triangles, frontal teeth, aesthetic risk

\section{INTRODUCTION}

The aesthetic requirements of the patient and dentist for dental treatment constantly increase nowadays. The characteristics of the gingival and bone architectonics have a decisive role for the aesthetic risk of both periodontal treatment (non-surgical and surgical) and dental implant therapy.

Dental implants are often used in the contemporary dental treatment for single-tooth replacement in the aesthetic zone of the maxilla. Implant therapy in the anterior maxilla is considered an advanced or complex procedure and requires comprehensive pre-

\footnotetext{
Address for correspondence:

Irena Georgieva

Faculty of Dental Medicine

Medical University of Varna

84 Tsar Osvoboditel Blvd

9000 Varna

e-mail:dr.irenageorgieva@mail.bg
}

Received: April 5, 2017

Accepted: May 12, 2017 operative planning and precise surgical execution. The researchers suggest different treatment options to the clinicians that facilitate implant therapy in the case of interdental gingiva deficiency in the aesthetic zone of the maxilla. Both the height and the thickness of the interdental gingiva as well as the interdental bone plate infuence the preoperative planning.

The aesthetic result of the implant therapy in the aesthetic zone of the maxilla is highly dependent on the height of the present interdental papillae. Therefore, the predictability of the aesthetic results of an implant therapy is greater after a precise clinical and radiographic assessment of the area that needs restoration. The accurate assessment of the height of interdental papillae is important for the correct treatment planning, which helps determine the accurate diagnosis and reduce the aesthetic risk.

Preserving papillae in the gingival embrasures of the aesthetic zone is a key consideration in restorative, orthodontic and implant treatment.

Interdental papilla is the gingival portion, which occupies the space between two adjacent teeth. Mor- 
Interdental Papillae Height Assessment in the Aesthetic Zone of the Maxilla

phologically, the papilla was described first in 1959 by Cohen. In the incisor area of the maxilla, the interdental papillae have a pyramidal shape with a tip located immediately upon the contact point. The loss of interdental papillae can create phonetic problems, as well as cosmetic deficiencies (the so-called black triangles disease) (1).

According to Olsson et al., the base of the papilla in individuals with healthy periodontium is determined from the line, connecting the most apical points of the gingival margin to two adjacent teeth. The height of the interdental papilla is the distance from the base of the papilla to the tip. In the cases of present recessions these assessments are different (2).

Understanding the underlying etiology is essential to reducing the frequency and severity of open gingival embrasures. There is an open embrasure when the embrasure space is not completely filled with gingival tissue. In an adult population with a history of periodontal disease, open gingival embrasures are a common occurrence. Black triangles occur in more than one-third of the adults (3).

The etiology of open gingival embrasures is multifactorial. Potential causes include dimensional changes of the papilla during orthodontic alignment, loss of periodontal attachment resulting in recession, loss of height of the alveolar bone relative to the interproximal contact, length of embrasure area, root angulations, interproximal contact position and triangular-shaped crowns (3).

Open embrasures are found to be age-related. Studies have shown that patients over 20 years of age are more susceptible than people below 20 years of age. Open embrasures are found in $67 \%$ of the population over 20 years of age compared with $18 \%$ in the population under 20 years of age. Age is a significant risk factor leading to wide and long embrasure spaces in adults (3).

Divergent roots have a strong association with open gingival embrasures. One study of Cardaropoli et al. showed that mean root angulations in normal gingival embrasures converge at $3.65^{\circ}$ and an increase in root divergence by $1^{\circ}$ raises the probability of an open gingival embrasure by 14 to $21 \%$. With orthodontic treatment, maxillary incisor roots could be paralleled to reduce or eliminate open gingival embrasures (4).
Patients with triangular crown morphology are more susceptible to open embrasure spaces. Interproximal contact between central incisors is located at the incisal $1 \mathrm{~mm}$ of the crown. Interproximal reduction of enamel on triangular crowns will convert a point contact to a broader contact area that will reduce open gingival embrasures. Interproximal reduction and space closure will lengthen the contact point and move the contact gingivally (3).

Periodontal disease has been associated with loss of the interdental papilla because of alveolar bone loss. A distance of $5 \mathrm{~mm}$ from the alveolar crest to the contact point is considered periodontally healthy. In periodontal disease, the loss of bone increases the distance between the contact point and the alveolar crest, resulting in an open gingival embrasure. However, when the distance was more than $7 \mathrm{~mm}$, papilla was missing in most of the cases. At $6 \mathrm{~mm}$, papilla was present in half of the cases (5).

Toothbrush trauma may also cause open embrasures. If the loss of papillary height is because of trauma during tooth brushing, interproximal cleaning should be discontinued until the tissue can recover. Nontraumatic plaque control is recommended for patients susceptible to black triangles (3).

Identifying the aetiology of the "black triangle disease" may involve more than one approach. First, it is advisable to evaluate the papilla height and compare it with the adjacent papilla. If there are no discrepancies in the vertical dimension, then the problem is most likely the tooth shape or the angulation of the tooth root (Kokich 1996) (3).

There are invasive and non-invasive methods for determining the height of interdental papillae (6).

It is considered that the ideal height of the interdental papilla is between $4.5 \mathrm{~mm}$ and $5 \mathrm{~mm}$ or half of the crown length (7).

In order to assess the interdental/inter-implant papillary loss or regeneration, several classification systems have been proposed. Nordland \& Tarnow (1998) developed a classification system for the loss of papillary height, which uses as reference points the facial and interproximal cementoenamel junction (CEJ) of natural teeth and the interdental contact point: 
Irena Georgieva, Stefan Peev, Teodora Gerova et al.

$\diamond$ class I - papillary loss was defined when the tip of the papilla was found between the contact point and the interproximal CEJ (with no visual appearance of the interproximal CEJ).

$\diamond$ class II - papillary loss involves the presence of the tip of the papilla at or apical to the interproximal CEJ but coronal to the facial CEJ.

$\diamond$ class III - papilla disappearance at or below the level of the facial CEJ (1).

This classification may be of importance for clinicians when trying to evaluate the success of different existing treatment modalities to enhance soft-tissue aesthetics $(1,8)$.

Currently, there are no predictable surgical procedures to augment papilla. Surgical papillary reconstruction may result in contraction and necrosis of the grafted tissue. The unpredictability is due to tissue fragility and low blood supply to the interdental papilla. Flap pedicles have shown better results than free gingival grafts. For surgical success, it is important that there is a presence of a thick biotype gingiva and there is no loss of insertion at the periodontal attachment. Patients with a thin biotype of gingiva are more susceptible to recession and therefore, to open gingival embrasures. The thick periodontal biotype has a thick osseous structure with flat morphology and a thick gingival tissue with short wide papilla. In contrast, the thin biotype is characterised by a scalloped appearance with long interdental papilla. Typically, the thick biotype has a better vascular supply and biological tissue memory that helps the tissue to rebound, whereas the thin biotype usually results in permanent recession (3).

\section{MATERIALS AND METHODS}

The aim of this epidemiologic study is to investigate the height of the interdental papilla between the maxillary frontal teeth in the aesthetic zone of the upper jaw and also to generalise the variations in the height of these interdental papillae. In addition to this, it tries to determine the significance of these variations regarding aesthetic risk for implant therapy in this zone.

The study includes only interdental papillae between the upper frontal teeth in the aesthetic zone of the maxilla of 220 individuals (80 males and 140

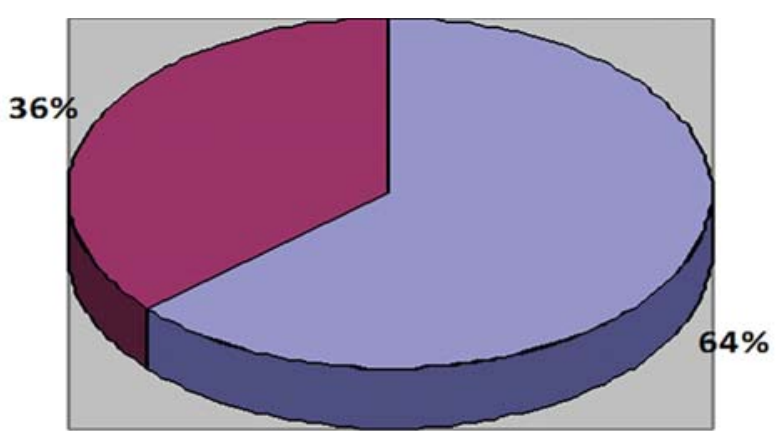

\section{$\square$ females $\square$ males}

Figure 1. Sex distribution of examined patients

females). The sex distribution shows $63.3 \%$ females and $36.7 \%$ males.

The individuals in the test group are between 18 and 75 years old (mean age 37.4 years). The age distribution shows 46 patients under 25 years, 127 patients between 26 and 45 years, and 47 patients over 45 years.

The test group includes only patients, who respond to the following criteria:

$\diamond$ all participants in the study have permanent dentition in the frontal sextant of the maxilla;

$\diamond$ all of them have intact upper frontal teeth there are no missing or decayed teeth in the upper frontal sextant;

\section{$21 \%$}

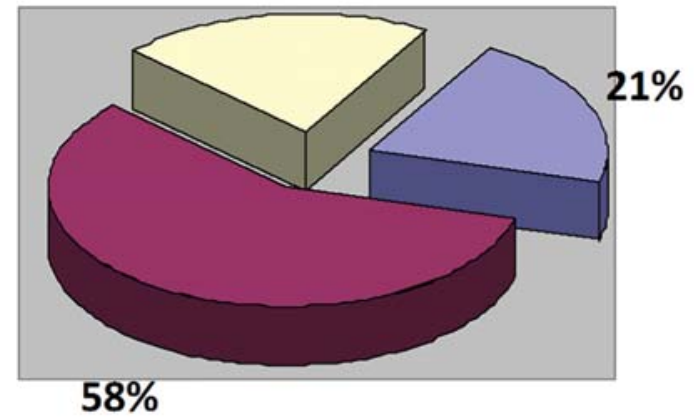

under 25 y. $\square$ 26-45 y. $\square$ over 45 y.

Figure 2. Age distribution of examined patients 
Interdental Papillae Height Assessment in the Aesthetic Zone of the Maxilla

$\diamond$ there are non-restored natural upper frontal teeth (without crowns/bridges/interproximal fillings).

Potential subjects who meet any of the following criteria will be excluded from participating in the study:

$\diamond$ take medicaments that increase the risk of gingival enlargement;

$\diamond$ patients with teeth crowding;
The received data of the conducted study are summarised in Table 1 and Figure 3:

We registered the following results of the height of the interdental papillae in the frontal sextant of the upper jaw relative to the age of the assessed patients:

$\diamond$ under 25 years old: the number of the papillae with normal height is 201 (90\%), papillae class I - 23 (10\%) and no papillae class II and class III are registered;

Table 1. Distribution of the height of interdental papillae

\begin{tabular}{lccc|c} 
Interdental papilla & Class I & Class II & Class III & Normal Height \\
$(\mathbf{n})$ & 344 & 116 & 44 & 538 \\
$\%$ & 33 & 11 & 4 & 52 \\
\hline
\end{tabular}

$\diamond$ patients with missing frontal teeth;

$\diamond$ patients with restored anterior maxillary teeth.

In all individuals in the test group, in the aesthetic zone of the maxillae, the height of interdental papillae is assessed according to the classification of Nordland \& Tarnow (1998). Based on this classification, the assessments are divided into 4 groups:

$\diamond$ normal papilla height - the interdental papilla fills the whole interdental space and reaches the contact point;

$\diamond$ class I papillary loss - defined when the tip of the papilla was found between the contact point and the interproximal CEJ (with no visual appearance of the interproximal CEJ);

$\diamond$ class II papillary loss - involves the presence of the tip of the papilla at or apical to the interproximal CEJ but coronal to the facial CEJ;

$\diamond$ class III papillary loss - papilla disappearance at or below the level of the facial CEJ.

\section{RESULTS}

In the assessment of 1088 interdental papillae for all 220 females and males, we received the following results:

550 of all investigated papillae have normal height (52\%), while in another 538 papillae there is a loss of papillary height (48\%). Out of the last group:

$\diamond 344$ of these 538 papillae are class I (33\%);

$\diamond 116$ papillae - class II (11\%);

$\diamond 44$ papillae - class III (4\%).

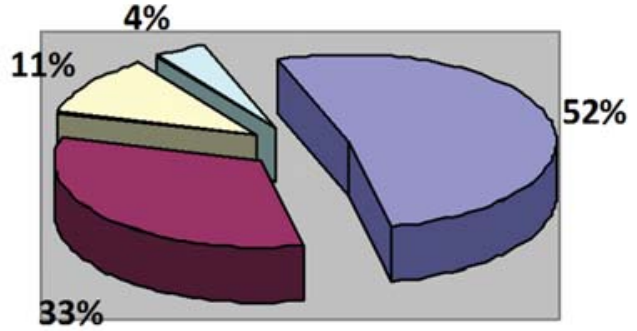

\section{$\square$ normal height $\square$ class $1 \square$ class $2 \square$ class 3}

Figure 3. Distribution of all classes interdental papillae in the assessed test group patients (Nordland \&Tarnow, 1998)

$\diamond$ between 26 and 45 years old: papillae with normal height - 305 (51\%), papillae class I - 222 (37\%), papillae class II - 62 (10\%) and papillae class III - 13 (2\%);

$\diamond$ in the group of age over 45 years old: papillae with normal height - $44(21 \%)$, class I - 99 (47\%), papillae class II - 54 (26\%), and papillae class III - 13 (6\%).

The received data of the conducted study are summarised in Table 2:

\section{DISCUSSION}

One of the aims of surgical and restorative dental treatment is the achievement of intact interdental papillae with normal height. The differences in 
Irena Georgieva, Stefan Peev, Teodora Gerova et al.

Table 2. Distribution of the height of interdental papillae according to the loss of height in the different age groups

\begin{tabular}{lcc|cc} 
Age & Normal Height & Class I & Class II & Class III \\
$<\mathbf{2 5} \mathbf{y .}$ & 201 & 23 & 0 & 0 \\
$\mathbf{2 6} \mathbf{- 4 5}$ y. & 305 & 222 & 62 & 13 \\
$>\mathbf{4 5} \mathbf{y}$. & 44 & 99 & 54 & 13 \\
\hline
\end{tabular}

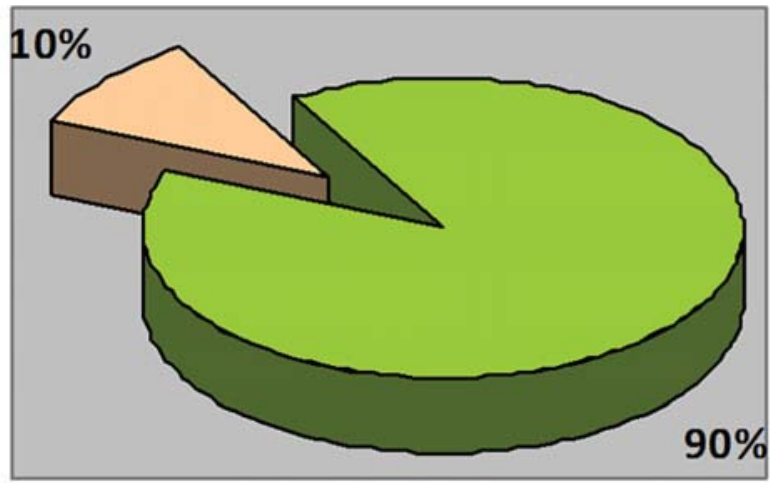

\section{normal height $\square$ class 1}

Figure 4. Distribution of the height of interdental papillae in the age group under 25 years old

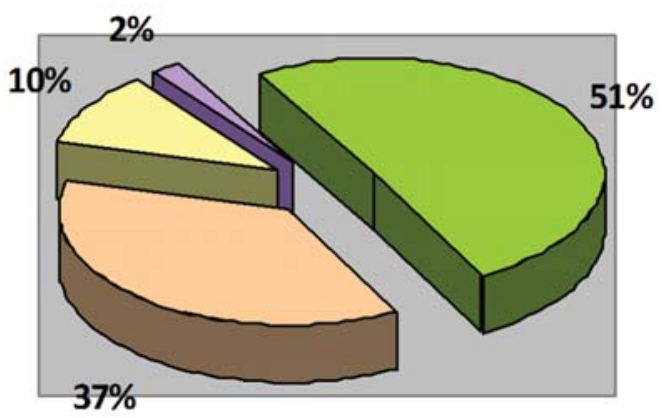

\section{normal height $\square$ class $1 \square$ class $2 \square$ class 3}

Figure 5. Distribution of the height of interdental papillae in the age group between 26 and 45 years old

height of interdental papillae and underlying interdental bone have a decisive meaning for the aesthetic result of implant and periodontal treatment.

The meticulous treatment planning is important for the achievement of interdental papillae with

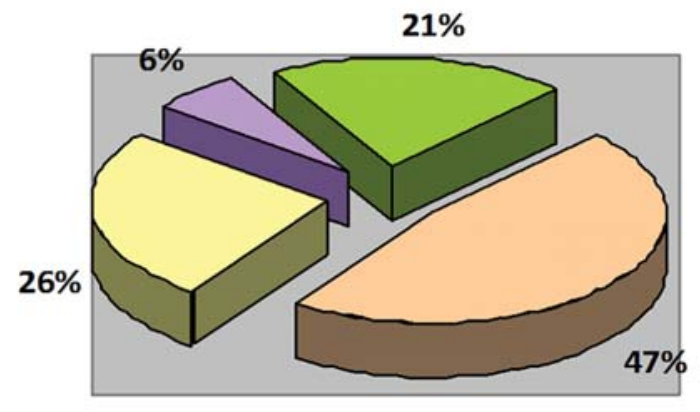

normal height $\square$ class $1 \square$ class $2 \square$ class 3

Figure 6. Distribution of the height of interdental papillae in the age group over 45 years old

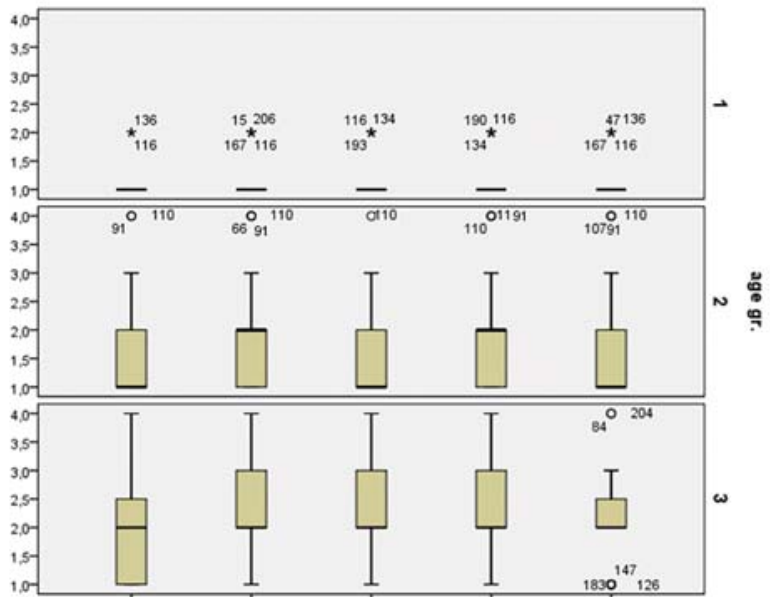

Figure 7. Variations of height of interdental papillae in various age groups

normal height. The best predictability for good aesthetic result after surgical and implant therapy, will be achieved in patients who initially have interdental papillae with normal height.

According to the results from the study, 52\% of all assessed papillae have normal height (Fig. 3) and in these cases the aesthetic risk for failure of the 
Interdental Papillae Height Assessment in the Aesthetic Zone of the Maxilla

planned therapy will be lower (Table 1). In all other cases (48\%), when we have little or more interdental papillary loss in the aesthetic zone of the maxilla, that means in cases of class I, class II or class III interdental papillary loss, we may expect the appearance of the so-called "black triangles" in interproximal spaces, which are a serious aesthetic problem (Fig. 3).

The interdental papilla height is important also for the surgical methods of treatment of root coverage. In cases of class I and class II interdental papillae there is an aesthetic risk for failure as a result of planned surgical treatment. These are $44 \%$ of the assessed papillae. In cases of class 3 interdental papillae (4\%) there will be contraindications for mucogingival surgical treatment for root coverage.

The results from the hold study confirm that the frequency and severity of interdental papillary loss increase with age. Not surprisingly the group of over 45 years of age has the highest frequency of class III interdental papillae (6\%) (Fig. 6).

Therefore, with the increase of age the predictability of the aesthetic result of implant therapy in the aesthetic zone of maxilla decreases. That is why the meticulous determination of the interdental papilla height is very important for the correct preoperative treatment plan of implant therapy. The height variations in the different age groups are presented on Fig. 7.

\section{CONCLUSION}

The results show that the frequency and severity of interdental papillae height loss increase with age and in the age group of over 45 years the distribution of interdental papillae class III is greatest (6\%).

\section{REFERENCES}

1. Zetu L, Wang HL. Management of inter-dental/inter-implant papilla. J Clin Periodontol. 2005; 32(7): 831-839. doi: 10.1111/j.1600-051X.2005.00748.x

2. Chang L. Factors associated with the interdental papilla height between two maxillary central incisors: a radiographic study. J Periodontol. 2012; 83(1):43-49. doi: 10.1902/jop.2011.100574

3. Sharma AA, Park JH. Esthetic considerations in interdental papilla : remediation and regeneration. J Esthet Restor Dent. 2010;22(1):18-28. doi: 10.1111/j.1708-8240.2009.00307.x
4. Cardaropoli D, Re S. Interdental papilla augmentation procedure following orthodontic treatment in a periodontal patient. J Periodontol. 2005; 76(4): 655-61. doi: 10.1902/jop.2005.76.4.655

5. Singh VP, Uppoor AS, Nayak DG, Shah D. Black triangle dilemma and its management in esthetic dentistry. Dent Res J (Isfahan). 2013;10(3):296-301.

6. Al-Harbi SA. Nonsurgical management of interdental papilla associated with multiple maxillary anterior implants: a clinical report. J Prosthet Dent. 2005; 93(3):212-16. doi: 10.1016/j. prosdent.2004.12.015

7. Prato GP, Rotundo R, Cortellini P, Tinti C, Azzi R. Interdental papilla management and classification of the therapeutic approaches: a review. Int J Periodontics Restorative Dent. 2004;24(3):246-55. doi: 10.1016/j.prosdent.2004.07.002

8. Greenstein G, Cavallaro J, Tarnow D. When to Save or Extract a Tooth in the Esthetic Zone: A Commentary. Compend Contin Educ Dent. 2008;29(3):136-45. 